\title{
TOWARDS EQUITABLE REPRESENTATION OF WOMEN IN EngineEring AT A TeChNiCAL Institution: A CASE STUDY
}

\author{
Katherine Golder and Joanna Wallace \\ British Columbia Institute of Technology \\ katherine_golder@bcit.ca, joanna@plasmatic.ai
}

\begin{abstract}
In North America, women account for a low percentage of the student population in technology-related fields such as computer science and engineering. While rates of women enrolled in these programs have risen since 1980, the fields remain male-dominated. Why are women so underrepresented in engineering?

Technical institutions, such as MIT, have been able to achieve near gender balance in some of their programs. While this was a goal MIT strived for over the past 15 years, it shows that common reasons for reduced enrollment rates of women may be addressed by the institutions themselves.

As a polytechnic institution offering trades, diploma, and accredited degree programs, the institution described in this case serves students from a wide variety of backgrounds with a wide variety of career goals. But the number of women in these programs remains low. We hope that by implementing programs and methods proven to improve enrollment rates of women at other institutions $B C I T$ will be able to increase the number of women in their engineering programs.

This paper includes an overview of the institute, an outline of some of the broader context of engineering education in North America, a description of an intervention carried out by the authors, as well as preliminary survey and discussion results from the intervention. This paper offers first steps for others who may want to facilitate discussion at their institutions.
\end{abstract}

Keywords: Women, STEM, Technical Institutions, Gender Balance, Equity

\section{INTRODUCTION}

As engineering educators, we cannot help but be aware of the underrepresentation of women in most, if not all, engineering programs [1]. But addressing this issue and improving the gender balance in post-secondary engineering programs can seem challenging, if not impossible.

This paper begins to explore this issue in the case of the British Columbia Institute of Technology (BCIT), a large polytechnic institute in the Metro Vancouver Regional
District. This includes an overview of the institute, an outline of the broader context, a description of an intervention carried out by the authors to promote awareness and discussion, as well as some preliminary survey and discussion results. Our goal with this paper is to offer some first steps for those at other institutions who want to initiate change, and to encourage others to share stories and advice with us.

\subsection{The Context at the British Columbia Institute of Technology}

The British Columbia Institute of Technology (BCIT) began as a vocational school in 1960 and merged with the Pacific Vocational Institute in 1986 [2]. BCIT currently offers certificates, diplomas, and undergraduate and graduate degrees in a wide variety of fields. These are offered in full- and part-time programs, with the majority of BCIT's students enrolled in part-time studies.

BCIT is an inclusive institution in that it strives "to make the benefits of a BCIT education available to all who come to the institute prepared to meet our high standards." Its mission includes "educating and training graduates who are career-ready" so that graduates can support a decent standard of living [3]. If BCIT is to be truly inclusive, it must take steps to identify and mitigate barriers to gender diversity in engineering and technology. For the economic and social health of the province, women must also have access to "the entry-to-practice credentials that lead to rewarding careers" and "support a decent standard of living" [3].

\subsection{Comparison of BCIT to National Enrollment Statistics}

Several engineering degree programs have been accredited at BCIT, with more going through the accreditation process. In this paper, we will focus on the currently accredited Bachelor of Engineering programs at BCIT: Civil, Electrical, and Mechanical, which were accredited in 2010, 2011 and 2014 respectively. BCIT offers Bachelor of Science programs and Bachelor of 
Technology programs, but these will not be considered here.

In Canada in 2016, 14,905 undergraduate engineering degrees were awarded. Of these, 2,882 were to women [1]. In civil, electrical, and mechanical engineering programs in Canada, the 2016 national average for female enrollment was $14.3 \%, 12.9 \%$, and $25.1 \%$ respectively. BCIT's programs had a lower rate of female enrollment in 2016 at $6 \%, 5 \%$, and $14 \%$ respectively. Taken together, the rate of female enrollment in accredited Bachelor of Engineering programs in 2016 at BCIT was $8 \%$. These BCIT rates are shown in Fig 1.

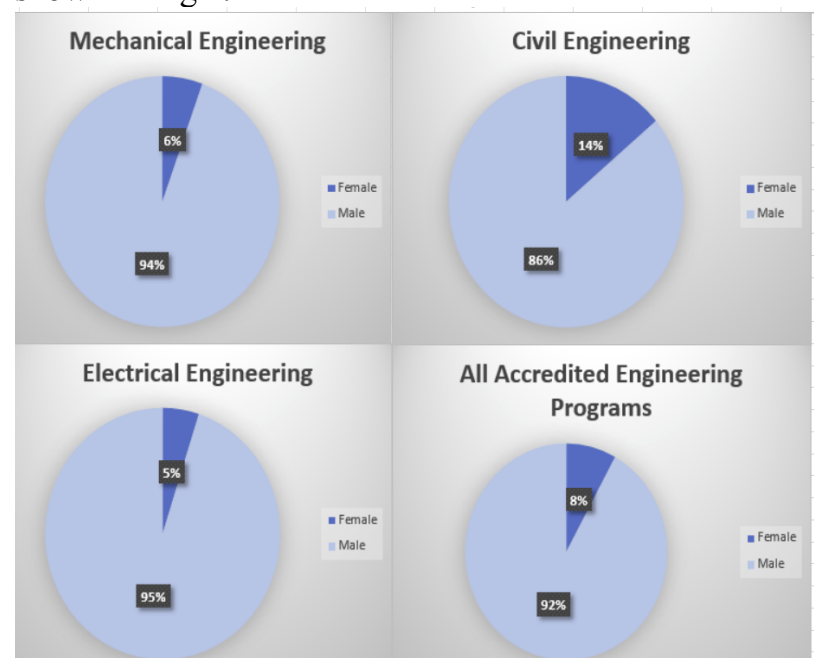

Fig 1: Percentage of women enrolled in the accredited engineering degree programs at BCIT in 2016

Canada has 49 accredited universities or institutions which offer some engineering program. Of these, six could be classified as polytechnic institutions like BCIT. The enrollment rates in each of these institutions' engineering programs are shown in Fig 2 [1].

Except for Polytechnique Montreal, these schools tend to have lower than average enrollment rates when compared to all accredited schools in Canada. Polytechnique Montreal has also been working formally since 1998 to encourage more women to enroll in the school [4].

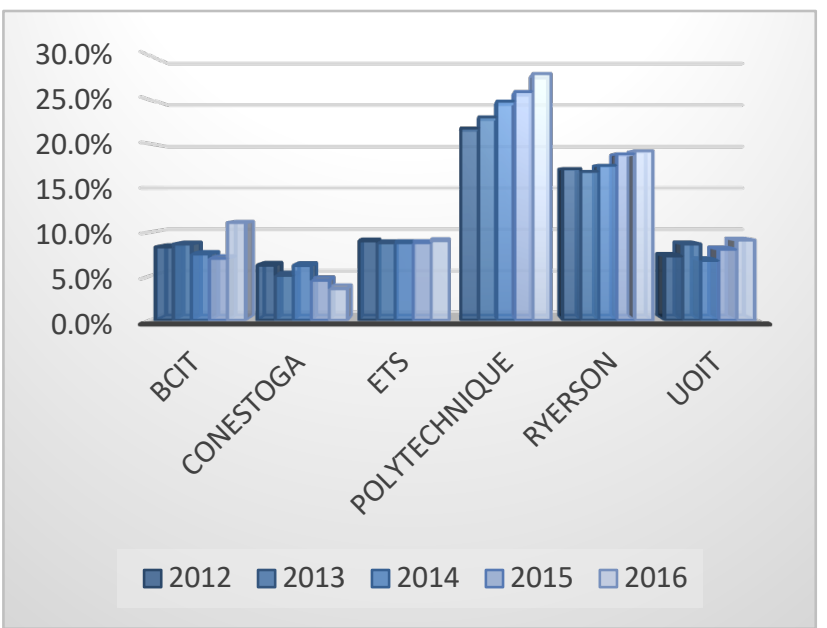

Fig 2: Percentage of women enrolled in accredited engineering programs run by technical institutions in Canada

\subsection{Interventions Applied at Other Institutions}

Some institutions in North America have been successful at achieving near-gender parity in some engineering programs. The Massachusetts Institute of Technology (MIT) department of Mechanical Engineering was comprised of $49.5 \%$ women in 2016 [5]. In Canada, the school with the highest female enrollment in engineering was the University of Northern British Columbia (UNBC) which had a $42.1 \%$ female engineering enrollment in 2016 [1]. Both of these schools have undertaken initiatives to encourage female enrollment [5] [6] [7].

Research from institutions with initiatives to encourage more female enrollment has identified some methods that have been effective. These include:

- Challenging the assumption that males are dominant on campus which is often held by potential applicants [5]

- Providing female-only courses for high school students [8]

- Hiring a more gender-balanced faculty [5] and providing access to role models ("existence proofs") and mentorship [5] [9]

- Including "applications and context in the introductory courses of technical subjects" [10]

- Raising awareness of the gender gap as an issue with faculty and staff [5]

\subsection{Current Interventions at BCIT}

BCIT has programs in place which encourage women to enter the trades [10] [11], but these programs do not extend to the engineering departments. Beyond this, there are no official initiatives geared at increasing the enrollment of women in the engineering programs.

To start raising awareness of the issues faced by women in engineering and supporting the women currently 
enrolled, the authors assisted in the delivery of an event at BCIT intended to increase awareness of the gender gap, as prescribed by previous research [5]. Note that this project is not part of our paid workloads, nor is it driven by the institute.

\section{PANEL DISCUSSION: GENDER DIVERSITY IN ENGINEERING \& TECHNOLOGY}

Inspired in part by the Ontario Women in Engineering (ONWiE) presentation at the CEEA conference at the University of Toronto in 2017, we began raising awareness and fostering conversation with a panel presentation and discussion. This was done with the support of an existing framework on campus, a SSHRC-funded initiative called Diversity Circles [13].

\subsection{Panel Structure and Discussion Questions}

The event was more successful than we expected, drawing a big enough audience (roughly 75 people, including faculty, staff, students, and managers) that we had to turn people away at the door. The panel was moderated by one of the authors of this paper, Joanna Wallace. The panelists were each given a question to prepare an answer to:

- A faculty member and one of her research assistants responded to, "You've been researching strategies for improving women and girls' participation in science, technology, engineering, and math ("STEM" for short). What are some of your most interesting findings? Why do women and girls leave STEM? What would attract them to STEM?"

- A recent Electrical and Computer Engineering Technology diploma graduate responded to, "Why is better representation of gender diversity (women and LGBTQ+ engineers) important to engineering and tech? How does greater diversity benefit the practice of engineering?"

- A Civil Engineering bachelor's student who cochairs the Women in Engineering club on campus responded to, "What does the Women in Engineering club do? How do student clubs like Women in Engineering and Coding for All help enrich the experiences of students in engineering and tech? What kind of feedback do you hear from your members?"

- The associate dean of Computing responded to, "You're described as 'a champion of getting girls into technology-presenting at events like Microsoft DigiGirlz Day-and, as a co-organizer of the 2007 international Women in Machine Learning Workshop: Keeping Them in Tech.' In your experience, what helps attract women and girls to tech and what keeps them there? If you could do one thing to get more women into tech at BCIT, what would it be?"

- The final presenter, a practicing engineer, public figure, and trans activist responded to, "Why do you think women are underrepresented in engineering, and how does this intersect with underrepresentation of LGBTQ2+ engineers?

After the first three panelists spoke, we paused for 20 minutes for attendees to participate in discussions at each table. We suggested two guiding questions:

1. Engineers Canada, along with many companies and post-secondary institutions, has published a plan and targets to help increase the number of women in Engineering. What immediate steps should BCIT take to get on board?

2. What information and research do we need to gather to better address this question?

Each table was provided flipchart paper and markers to take notes. These notes were transcribed and are discussed below. We also conducted a brief survey of attendees, and some of the preliminary results are described below. More details and a video of the full panel presentation can be found here [13].

\subsection{Comments and Recommendations from the Roundtable Discussions}

The recommendations generated during the roundtable discussions fell into three broad categories: providing education for students and faculty about the issues, including training on avoiding "casual sexism" and creating inclusive classrooms; increasing promotion and outreach to attract more women to engineering programs; and recommending actions that the institute's leadership and administrators can take, including providing more services and support, such as expanded childcare options, hiring more women faculty members, and establishing an equity office.

\subsection{Survey Results}

Based on informal feedback and the surveys conducted at the event, the panel presentation and discussion were well received. Out of the roughly 75 attendees, 45 surveys were returned. Most survey respondents were faculty members, followed by students, then staff, and three managers, as shown in Appendix A. Not all of the respondents study engineering or work with engineering students, but the majority (56\%) do. The survey was very small and was mainly intended to help us decide on future directions for our work.

The results are not intended to be generalizable, but they may be helpful to others who would like to start a 
similar initiative at their institute. The results will be analyzed further to help direct future events and identify recommendations for the institute, but our preliminary review has provided some helpful insights:

Most attendees who responded to the survey said they went to the Diversity Circle because they recognize it is an important topic and want to show support for the cause. The next largest category was people wanted to learn more. Most of those who responded to the survey mentioned that the most valuable part of the event was hearing the stories and experiences of the presenters and others in the room. This was followed respondents who identified the most valuable part as seeing how much support there is at BCIT that they didn't know was there.

The value placed on support and connection lines up with a comment by an ONWiE representative at CEEA in 2017: Even if the intervention you employ (a workshop, training session, presentation, etc.) to address the underrepresentation of women in engineering does little to change the minds or behaviour of those who might be contributing to the problem, it has the benefit of making the women in the room feel heard and validated. Several of the women students in attendance said the panel presentation and discussion came as a relief to them.

Interestingly, two thirds of the respondents said they were unaware of initiatives at Engineers Canada, some companies, and other post-secondary institutes to address the underrepresentation of women in engineering. This supports our decision to begin by raising awareness. While the underrepresentation of women is obvious to anyone who simply walks into an engineering class, the fact that organizations can, and should, develop a strategy for addressing this problem is less obvious.

By far the most common responses to "what would you recommend the organizers do differently next time" was "more time" - more time for a Q\&A with presenters, more time for the table discussions, more time to talk informally.

Further results can be found in Appendix A below.

\section{CONCLUSIONS}

Since the panel, other events have been organized on campus, some of which were influenced by the intervention described above. The BCIT Student Association's VP of Student Affairs was motivated to organize a speakers' series and workshops on campus to raise awareness [12]. A faculty member in Mechanical Engineering who was at the panel presentation has invited us to organize a smaller panel presentation for the Mechanical Engineering faculty to ensure that the entire department could benefit from the insights shared there.

The authors of this paper were awarded a small grant to continue gathering data about gender in engineering at BCIT, reading the literature on gender in engineering and researching what other post-secondary institutions are doing to tackle the problem, as well as presenting and facilitating workshops at BCIT.

As mentioned above, we were inspired to tackle this issue at BCIT by a comment made by a presenter at CEEA last year. Having seen some success and a great deal of support for our work at BCIT, we wanted to return to CEEA in gratitude for the inspiration and to provide some ideas for others considering similar projects.

\section{Acknowledgements}

We would like to acknowledge the support of the Diversity Circles initiative at BCIT (http://www.diversitycircles.com/) as well as the BCIT Learning and Teaching Centre and the Learning and Teaching Framework project.

\section{References}

[1] Engineers Canada, "Canadian Engineers for Tomorrow: Trendsin Engineering Enrolment and Degrees Awarded 2012-2016," Engineers Canada, Ottawa, 2016.

[2] The British Columbia Institute of Technology, "About the Institute: History," [Online]. Available: https://www.bcit.ca/about/history.shtml. [Accessed 30032018 ].

[3] The British Columbia Institute of Technology, "About the Institute: BCIT's Guiding Statements," [Online]. Available: https://www.bcit.ca/about/vision.shtml . [Accessed 3003 2018].

[4] Chaire Marianne-Mareschal, "Pour une envolee vers le monde fascinant de l'ingenierie!," Chaire Marianne-Mareschal, 2015. [Online]. Available: http://www.chairemm.polymtl.ca/mission.php. [Accessed 5 May 2018].

[5] K. Xu, D. Wendell and A. S. Walsh, "Getting to Gender Parity in a Top-Tier Mechanical Engineering Department: A Case Study," in American Society for Engineering Education, Columbus, OH, 2017.

[6] CKPGToday, "UNBC Promotes Engineering to Girls," CKTGToday, 5 October 2017. [Online]. Available: http://ckpgtoday.ca/article/503277/unbcpromotes-engineering-girls. [Accessed 30 April 2018].

[7] UNBC University of Northern British Columbia, "Youth at UNBC," UNBC, 14 October 2017. [Online]. Available: https://www.unbc.ca/youth/goeng-girl. [Accessed 30 April 2018].

[8] MIT, "Women's Technology Program," MIT, 1 Jan 2018. [Online]. Available: http://wtp.mit.edu/. [Accessed 30 April 2018]. 
[9] A. Kahl, "Brewing Change: A Forum for Women in Engineering and the Sciences," in American Society for Engineering Education, Columbus, OH , 2017.

[10] BCIT, "Trades Discovery for Women," BCIT, [Online]. Available: https://www.bcit.ca/study/programs/1190acert. [Accessed 30 April 2018].

[11] BCIT, "BCIT Renew: Five-Year Capital Plan 2015 to 2019," BCIT, Burnaby, 2014.

\section{APPENDIX A: SURVEY RESULTS}

Of the roughly 75 attendees at the panel presentation and discussion, 45 completed a survey about their knowledge and interest in the topic. Below we summarize answers that were quantifiable or had a limited set of responses from participants. The questions appear here as they did on the participant's form, though not necessarily in the same order.

When multiple answers were logged, both were counted individually in the results.

\section{A.1 Question 1}

How familiar are you with issues around gender diversity including women's and LGBTQ2+ people's underrepresentation in engineering (both in school and at the workplace)? 1 = Very familiar; $5=$ Not familiar at all

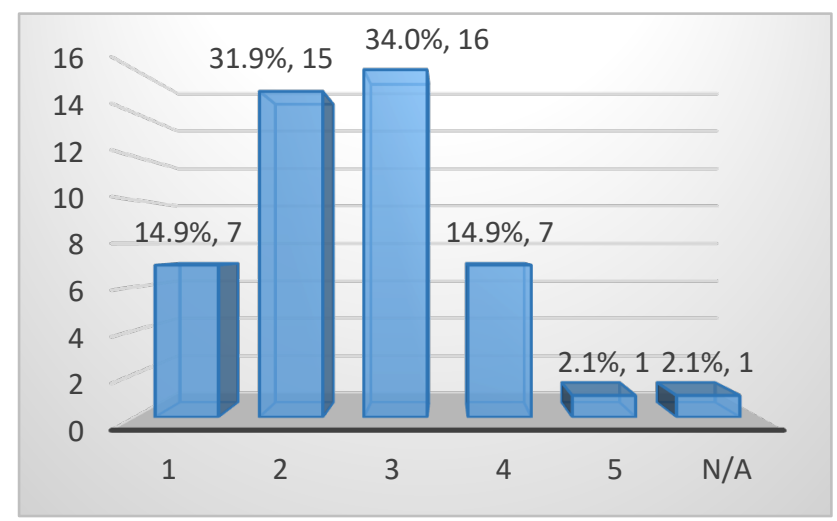

Fig 3: Survey results for Question 1 regarding familiarity with issues around gender diversity in engineering

\section{A.2 Question 2}

To what extent has your opinion on why so few women (and LGBTQ2+ people) practice engineering changed after hearing the panel and participating in the workshop? $1=$ Significantly; $5=$ Not at all
[12] BCIT Student Association, "Gender Equity Awareness," BCITSA, 2018. [Online]. Available: https://sites.google.com/view/campaigning/home?a uthuser $=1$. [Accessed 1503 2018].

[13] D. Hango, "Gender differences in science, technology, engineering, mathematics, and computer science (STEM) programs at university," Statistics Canada, Ottawa, 2013.

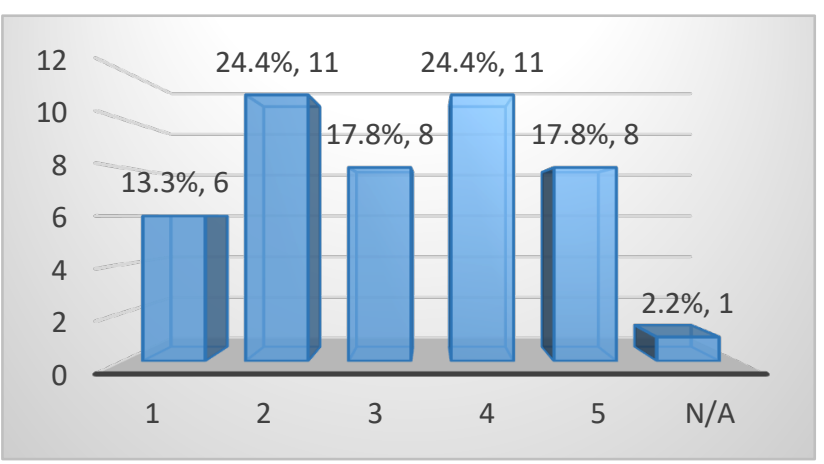

Fig 4: Survey results for Question 2 regarding any change of opinion on why so few women participate in the practice of engineering

Note that all of the respondents who said that their views had not changed commented that the panel presentation and discussion confirmed what they already knew.

\section{A.3 Question 3}

This was an open-ended question, but responses tended to be similar enough to do some preliminary coding and categorization. The categories are listed below and presented in a histogram.

Why do you think women and LGBTQ2+ people are underrepresented?

\begin{tabular}{|l|l|}
\hline A & Perception of male dominance in the industry \\
\hline B & $\begin{array}{l}\text { Lack of encouragement or education towards } \\
\text { engineering }\end{array}$ \\
\hline C & Existence of stereotypes or cultural blockers \\
\hline D & Lack of gender similar role models \\
\hline E & Fear of harassment or experience of harassment \\
\hline F & Unknown \\
\hline G & Perceived career inflexibility \\
\hline H & Misrepresentation of practice of engineering \\
\hline
\end{tabular}




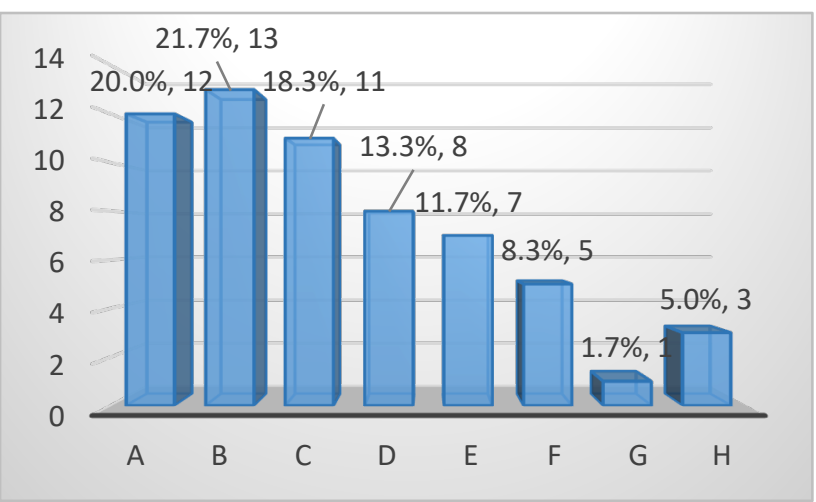

Fig 5: Survey results for Question 3 regarding suggested reasons for the underrepresentation of women in engineering

\section{A.4 Demographics}

To gain a better understanding of who participated in the survey, we gathered demographic data as well.

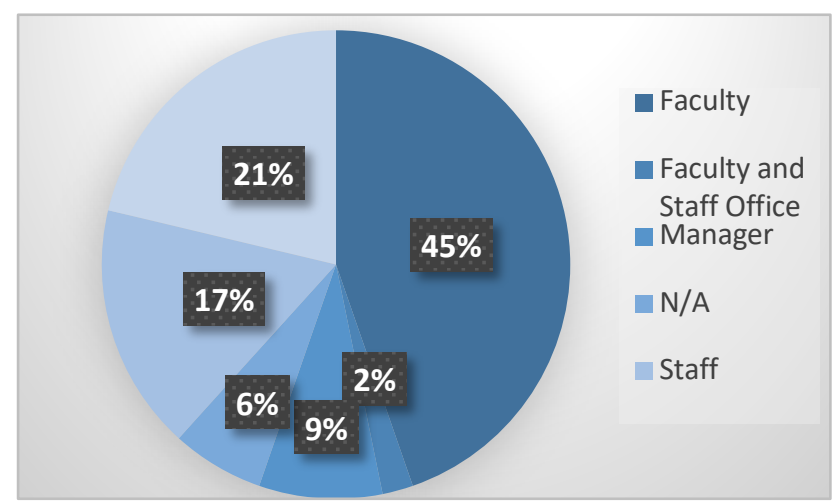

Fig 6: Survey participants' roles at BCIT 